\title{
Protective Effects of Bio-Active Ceramic Water on Alcohol-Induced Hepatic Injury in Pigs
}

\author{
Chang-Woo LEE ${ }^{1)}$, Won-Il JEONG ${ }^{1}$, Dong-Hyung NOH ${ }^{1)}$, Da-Hee JEONG ${ }^{1)}$, Sun-Hee DO ${ }^{1)}$, Yoo-Kyeong KIM ${ }^{2}$, \\ Oh-Deog KWON ${ }^{1)}$, Tae-Hwan $\mathrm{KIM}^{1)}$ and Kyu-Shik JEONG ${ }^{1) *}$ \\ ${ }^{1)}$ Department of Veterinary Pathology, College of Veterinary Medicine and ${ }^{2)}$ Teacher's College, Kyungpook National University, Daegu \\ 702-701, Republic of Korea
}

(Received 10 May 2004/Accepted 7 December 2004)

ABSTRACT. Among many detrimental injuries, alcohol is implicated in hepatitis, fatty liver, hepatic fibrosis, and cirrhosis. The purpose of this study was to evaluate the protective effect of bio-active ceramic water on alcohol-induced hepatic injury in pigs. Twelve male Landrace pigs were divided into 3 groups. Groups 1, 2, and 3 were fed with bio-active ceramic water + normal liquid diet, bio-active ceramic water + liquid diet containing $15 \%$ ethanol, and tap water + liquid diet containing $15 \%$ ethanol for 12 weeks, respectively. For serological, histopathological, and immunohistochemical analysis, all pigs were sacrificed at week 12. In group 3, serum ALT and AST levels increased, and mild fatty change and moderate necrosis were detected in the liver. Collagen fibers, myofibroblasts, and CYP2E1 were also increased or activated in group 3. In group 2, there were mild hepatic injuries compared to group 3 . However, injuries and activations were not observed in the liver in group 1. We suggest that the bio-active ceramic water used in the present study had protective capability against ethanol-induced hepatic injury and that having no toxic effect on the pig liver. The bio-active ceramic water might be useful as a therapeutic drinking water in patients suffering from alcoholic liver diseases.

KEY WORDS: active ceramic water, alcohol, fibrosis, liver, swine.

Hepatic disease is induced by various toxicants such as alcohol, drugs, microbiological agents and other xenobiotics. Alcohol has been noted for causing hepatitis, fatty liver, fibrosis, and hepatic cirrhosis $[15,21]$. Chronic ethanol ingestion increases blood markers such as aspartate aminotransferase (AST) and alanine aminotransferase (ALT), indicating hepatic dysfunction, and leads to hepatic fibrosis. These phenomena can be made by generation of free-radicals via alcohol dehydrogenase (ADH) and the microsomal ethanol oxidation system (MEOS) involving the cytochrome P450 2E1 (CYP2E1). Both the ADH and the MEOS pathways generate the toxic metabolic acetaldehyde, which forms adducts with proteins, resulting in enzyme inactivation, decreased DNA repair and antibody production, glutathione depletion, mitochondrial toxicity, impaired utilization of oxygen, and increased collagen synthesis [22]. Fibrosis due to chronic ethanol intoxication is always accompanied by excessive oxidation of polyunsaturated membrane lipids and activation of CYP2E1 [5]. Activated hepatic stellate cells (HSC) play a key role in the production of matrix in the normal and fibrotic liver $[6,13]$. They are activated by many stimulators such as inflammatory cytokines and growth factors [16]. Recently, many anti-fibrogenic agents such as $\mathrm{N}$-acethylcysteine, S-adenosyl methionine (SAMe), polyenylphosphatidyl choline (PPC), and anti-oxidants (silymarin, alpha-tocopherol and selenium) have been noted in alcoholic liver disease [7, 10]. Dietary supplementation with vitamin $\mathrm{E}$ has been shown to

\footnotetext{
* Correspondence to: Prof. Jeong, K.-S., College of Veterinary Medicine, Kyungpook National University, Daegu City 702701, Republic of Korea.
}

reduce hepatic fibrosis in alcoholic liver injury animal models, suggesting that liver fibrosis is closely related to oxidative stress [33]. In this report, we investigated the hepatoprotective potential of bio-active ceramic water made by manufactured stone for alcoholic liver injury in pigs. The data showed significant hepatoprotective effects of active ceramic water on the alcohol-induced hepatic injury in pigs.

\section{MATERIALS AND METHODS}

Animals and treatments: Bio-active ceramic water was made by passing normal tap water through bioactive multipurpose magnetized ceramic stones. The constituents of ceramics are described in Table 1. The present study was performed using twelve male Landrace pigs weighing approximately $5 \mathrm{~kg}$. All experimental procedures were performed in accordance with the NIH guidelines for the care and use of laboratory animals. Animals were divided into 3 groups $(n=4)$ and kept in three different pigpens at the College of Veterinary Medicine, Kyungpook National Univer-

Table 1. Composition of bioactive ceramic stone

\begin{tabular}{cccc}
\hline Constituent & $\%^{\mathrm{a})}$ & Constituent & $\%$ \\
\hline Silicic anhydride & 69.8 & $\mathrm{Mg}$ & 3.6 \\
Phosphoric anhydride & 0.3 & $\mathrm{CaO}$ & 2.0 \\
Inorganic resource & 0.88 & $\mathrm{Na}$ & 3.2 \\
$\mathrm{Al}_{2} \mathrm{O}_{3}$ & 14.0 & $\mathrm{~K}$ & 3.2 \\
$\mathrm{FeO}$ & 1.3 & $\mathrm{Ti}$ & 0.3 \\
$\mathrm{FeO}_{2}$ & 1.4 & $\mathrm{MnO}_{2}$ & 0.02 \\
\hline
\end{tabular}

a), $\%$ by total weight. 
Table 2. Liquid diet composition

\begin{tabular}{|c|c|c|c|c|}
\hline Week & $\begin{array}{c}\text { Average } \\
\text { body } \\
\text { weight } \\
(\mathrm{Kg})\end{array}$ & $\begin{array}{c}\text { Daily food intake (Calorie)/ } \\
\text { EtOH }\left(\text { Calorie }^{\text {a) }}\right) / \text { Total liquid diet }\end{array}$ & $\begin{array}{l}\text { Total calorie } \\
(\% \text { of EtOH) }\end{array}$ & $\begin{array}{l}\text { Dextrose }^{\mathrm{b})} \\
\text { (Calorie) }\end{array}$ \\
\hline 3 & 5 & $70 \mathrm{~g}(175 \mathrm{kcal}) / 4.5 \mathrm{ml}(24.2 \mathrm{kcal}) / 30 \mathrm{~m} l$ & $197.7 \mathrm{kcal}(11.5 \%)$ & $4.05 \mathrm{~g}(24.2 \mathrm{kcal})$ \\
\hline 4 & 7 & $235 \mathrm{~g}(270 \mathrm{kcal}) / 12 \mathrm{~m} l(64.8 \mathrm{kcal}) / 80 \mathrm{~m} l$ & $334.8 \mathrm{kcal}(19.4 \%)$ & $\begin{array}{c}16.2 \mathrm{~g} \\
(64.8 \mathrm{kcal})\end{array}$ \\
\hline 5 & 10 & $468 \mathrm{~g}(530 \mathrm{kcal}) / 13.5 \mathrm{~m} l(72.8 \mathrm{kcal}) / 90 \mathrm{~m} l$ & $602.8 \mathrm{kcal}(12.0 \%)$ & $\begin{array}{c}18.2 \mathrm{~g} \\
(72.8 \mathrm{kcal})\end{array}$ \\
\hline 6 & 14 & $615 \mathrm{~g}(700 \mathrm{kcal}) / 15 \mathrm{~m} l(80.9 \mathrm{kcal}) / 100 \mathrm{~m} l$ & $780.9 \mathrm{kcal}(10.4 \%)$ & $\begin{array}{l}20.225 \mathrm{~g} \\
(80.9 \mathrm{kcal})\end{array}$ \\
\hline 7 & 18 & $740 \mathrm{~g}(840 \mathrm{kcal}) / 30 \mathrm{~m} l(161.9 \mathrm{kcal}) / 200 \mathrm{~m} l$ & $1001.9 \mathrm{kcal}(16.2 \%)$ & $\begin{array}{c}40.475 \mathrm{~g} \\
(161.9 \mathrm{kcal})\end{array}$ \\
\hline 8 & 22 & $905 \mathrm{~g}(1030 \mathrm{kcal}) / 45 \mathrm{ml}(242.8 \mathrm{kcal}) / 300 \mathrm{~m} l$ & $1272.8 \mathrm{kcal}(19.1 \%)$ & $\begin{array}{c}60.7 \mathrm{~g} \\
(242.8 \mathrm{kcal})\end{array}$ \\
\hline 9 & 27 & $1110 \mathrm{~g}(1260 \mathrm{kcal}) / 60 \mathrm{ml}(323.8 \mathrm{kcal}) / 400 \mathrm{~m} l$ & $1583.8 \mathrm{kcal}(20.5 \%)$ & $\begin{array}{c}80.95 \mathrm{~g} \\
(323.8 \mathrm{kcal})\end{array}$ \\
\hline 10 & 32 & $1260 \mathrm{~g}(1430 \mathrm{kcal}) / 75 \mathrm{ml}(404.7 \mathrm{kcal}) / 500 \mathrm{~m} l$ & $1834.7 \mathrm{kcal}(22.1 \%)$ & $\begin{array}{l}101.175 \mathrm{~g} \\
(404.7 \mathrm{kcal})\end{array}$ \\
\hline 11 & 37 & $1460 \mathrm{~g}(1660 \mathrm{kcal}) / 90 \mathrm{~m} l(485.6 \mathrm{kcal}) / 600 \mathrm{~m} l$ & $2145.6 \mathrm{kcal}(22.6 \%)$ & $\begin{array}{c}121.4 \mathrm{~g} \\
(485.6 \mathrm{kcal})\end{array}$ \\
\hline 12 & 43 & $1600 \mathrm{~g}(1820 \mathrm{kcal}) / 105 \mathrm{ml}(566.6 \mathrm{kcal}) / 700 \mathrm{~m} l$ & $2386.6 \mathrm{kcal}(23.7 \%)$ & $\begin{array}{c}141.65 \mathrm{~g} \\
(566.6 \mathrm{kcal})\end{array}$ \\
\hline 13 & 49 & $1750 \mathrm{~g}(1990 \mathrm{kcal}) / 120 \mathrm{ml}(647.5 \mathrm{kcal}) / 800 \mathrm{~m} l$ & $2637.5 \mathrm{kcal}(24.6 \%)$ & $\begin{array}{l}161.875 \mathrm{~g} \\
(647.5 \mathrm{kcal})\end{array}$ \\
\hline 14 & 55 & $1900 \mathrm{~g}(2160 \mathrm{kcal}) / 135 \mathrm{ml}(728.5 \mathrm{kcal}) / 900 \mathrm{~m} l$ & $2888.5 \mathrm{kcal}(25.2 \%)$ & $\begin{array}{l}182.125 \mathrm{~g} \\
(728.5 \mathrm{kcal})\end{array}$ \\
\hline 15 & 61 & $2050 \mathrm{~g}(2330 \mathrm{kcal}) / 150 \mathrm{~m} l(809.4 \mathrm{kcal}) / 1000 \mathrm{~m} l$ & $3039.4 \mathrm{kcal}(26.6 \%)$ & $\begin{array}{c}202.35 \mathrm{~g} \\
(809.4 \mathrm{kcal})\end{array}$ \\
\hline
\end{tabular}

sity, with free access to specially designed autosupply tap water and the bio-active ceramic water system, which was designed with special ceramic stone. This ceramic stone can rapidly generate bio-active ceramic water sufficient for drinking water. Pigs were fed a freshly made liquid diet containing $15 \%$ ethanol three times per day at AM 08:00, PM 12:00, and PM 18:00 (Table 2). Groups were fed for 12 weeks with bio-active ceramic water + normal liquid diet (G1), bio-active ceramic water + liquid diet containing 15\% ethanol (G2), and normal tap water + liquid diet containing $15 \%$ ethanol (G3), respectively. At 12 weeks, all pigs were transported to a slaughter house and sacrificed for collection of tissue and blood samples.

Serological analysis: Blood from each pig was drawn at the time of sacrifice. Collected sera were immediately frozen at $-80^{\circ} \mathrm{C}$ until analysis. Serum ALT, AST, albumin and cholesterol were determined with an automated analyzer (Hitachi 736-10, Hitachi Co., Ltd). We referred the control values of ALT, AST, albumin, and cholesterol in normal pigs to the Text of Diseases of Swine [18, 19].

Histopathological analysis: Three pieces of the liver from each pig were quickly removed and fixed in $10 \%$ neutral buffered formalin, processed routinely and embedded in paraffin. Sections were cut to $4 \mu \mathrm{m}$ in thickness. Sections were stained with hematoxylin and eosin (H-E), and Azan stain. To evaluate the increase in quantity of collagen fibers, the width of collagen bundles were measured 10 different interlobular septa of three pieces of the liver randomly selected from each pig at 400-fold magnification per section, using an image analysis system (Matrox Graphics Inc., Quebec, Canada).

Immunohistochemistry: Sections of the liver were deparaffinized in xylene, dehydrated in graded alcohol series, and incubated in a solution of $3 \%$ hydrogen peroxide $\left(\mathrm{H}_{2} \mathrm{O}_{2}\right)$ in methanol for $10 \mathrm{~min}$. Tissue sections were washed in PBS containing $0.03 \%$ nonfat milk and $0.01 \%$ Tween 20 , and then immunostained with primary antibodies for $\alpha$-SMA at a dilution of 1:800 (Sigma Co, Saint Louis, MO, U.S.A.) and CYP2E1 at a dilution of 1:200 (Chemicon International, Inc., Temecula, CA, U.S.A.). The antigen-antibody complex was visualized by a labeled streptavidin-biotin method using a Histostatin-plus bulk kit (Zymed Laboratories Inc., San Francisco, CA, U.S.A.) with 3,3-diamino benzidine (Zymed Laboratories Inc., San Francisco, CA, U.S.A.). Tissue sections were then rinsed in distilled water and counterstained with Mayer's hematoxylin. Non-immunized goat sera were used instead of the primary antibody as the negative control.

Statistical analysis: Data were expressed as mean \pm SEM. For statistical analysis, $t$-test was employed. Values of $\mathrm{P}<0.05$ were considered significant. 
ALT

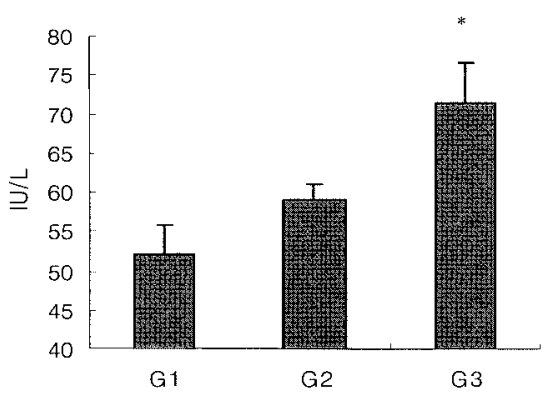

Albumin

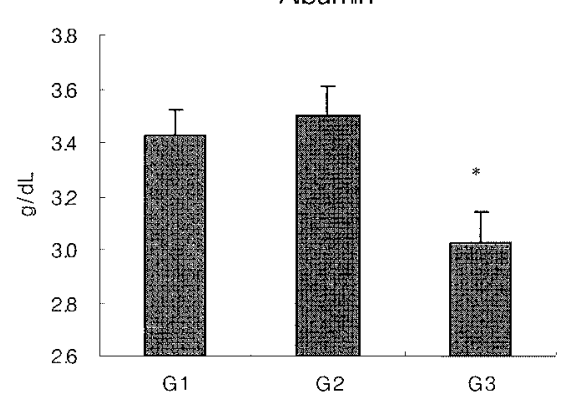

AST

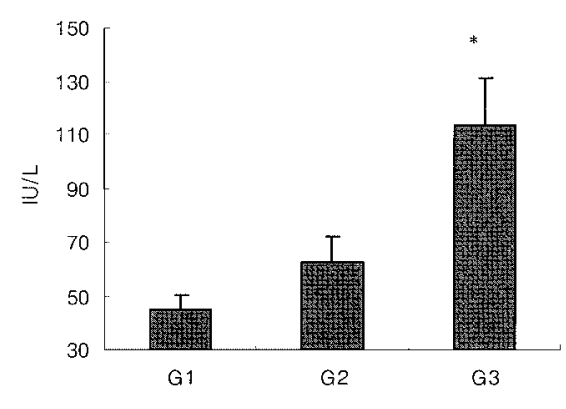

Cholesterol

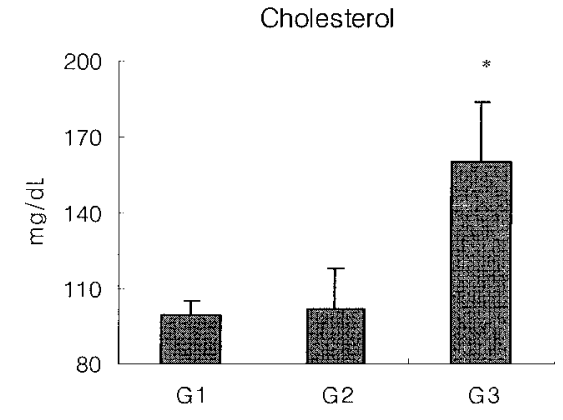

Fig. 1. Serological results on ALT, AST, albumin and cholesterol after 12 weeks of ethanol exposure. Data are presented as mean \pm SEM. ${ }^{*}, \mathrm{P}<0.05$, significance from the value of control. Normal porcine biochemistry reference intervals of feeder pigs on ALT, AST, albumin and cholesterol are as follows [18, 19]; ALT (15-46 U/L), AST (15-46 U/L), albumin (1.9-4.2 g/dL) and cholesterol $(40-128 \mathrm{mg} / \mathrm{dL})$. G1 is fed with active ceramic water + liquid diet, G2 with active ceramic water + liquid diet containing $15 \%$ ethanol and G3 with normal tap water + liquid diet containing $15 \%$ ethanol for 12 weeks, respectively.

\section{RESULTS}

Serological results: Normal porcine biochemistry reference intervals of feeder pigs on ALT, AST, albumin, and cholesterol are as follows [18, 19]; ALT (15-46 U/L), AST (15-46 U/L), albumin (1.9-4.2 g/dL), and cholesterol $(1.37-3.18 \mathrm{mmol} / \mathrm{L}$ or $40-128 \mathrm{mg} / \mathrm{dL})$. Serological results of the present study are shown in Fig. 1. Serum ALT and AST levels were significantly increased in G3 indicating hepatic insult, while they remained within normal range in G1 and G2. There were also increases of albumin synthesis in G1 and G2 as compared with G3. In G1 and G2, total cholesterol was also reversed to normal as compared with that of G3.

Histopathological results: Hepatic fatty change and fibrosis were successfully induced and identified in the ethanol-treated group (G3). The livers of G1 were within normal limits, and mild necrosis was observed in G2. G3 had mild fatty change in zone 1 region, while moderate necrosis was evident in regions of zones 2 and 3 . To determine the extent of fibrosis, Azan staining for collagen was carried out and the significance was shown by the data on the width of collagen bundles in the interlobular septa (Fig. 2). There was no necrosis or increase in collagen fibers in the livers of

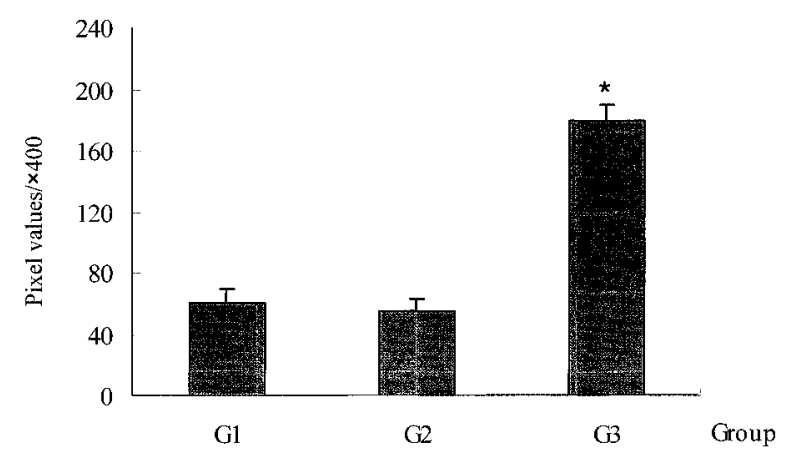

Fig. 2. Width on the bundles of collagen fibers in the interlobular septa. The width on the bundles of collagen fibers significantly increased in G3 as compared with G1 and G2. Data are presented as mean \pm SEM. Pixel values of G1 was considered as control, as described in the text of our study. 1 pixel $=0.17 \mu \mathrm{m}$; $*, \mathrm{P}<0.01$, significance from the value of $\mathrm{G} 1$.

G1, indicating that there was no hepatic toxicity or fibrogenic effect of bio-active ceramic water. On the contrary, necrosis was evident in G2 and G3, the latter being more prominent, and collagen fibers significantly increased in G3 

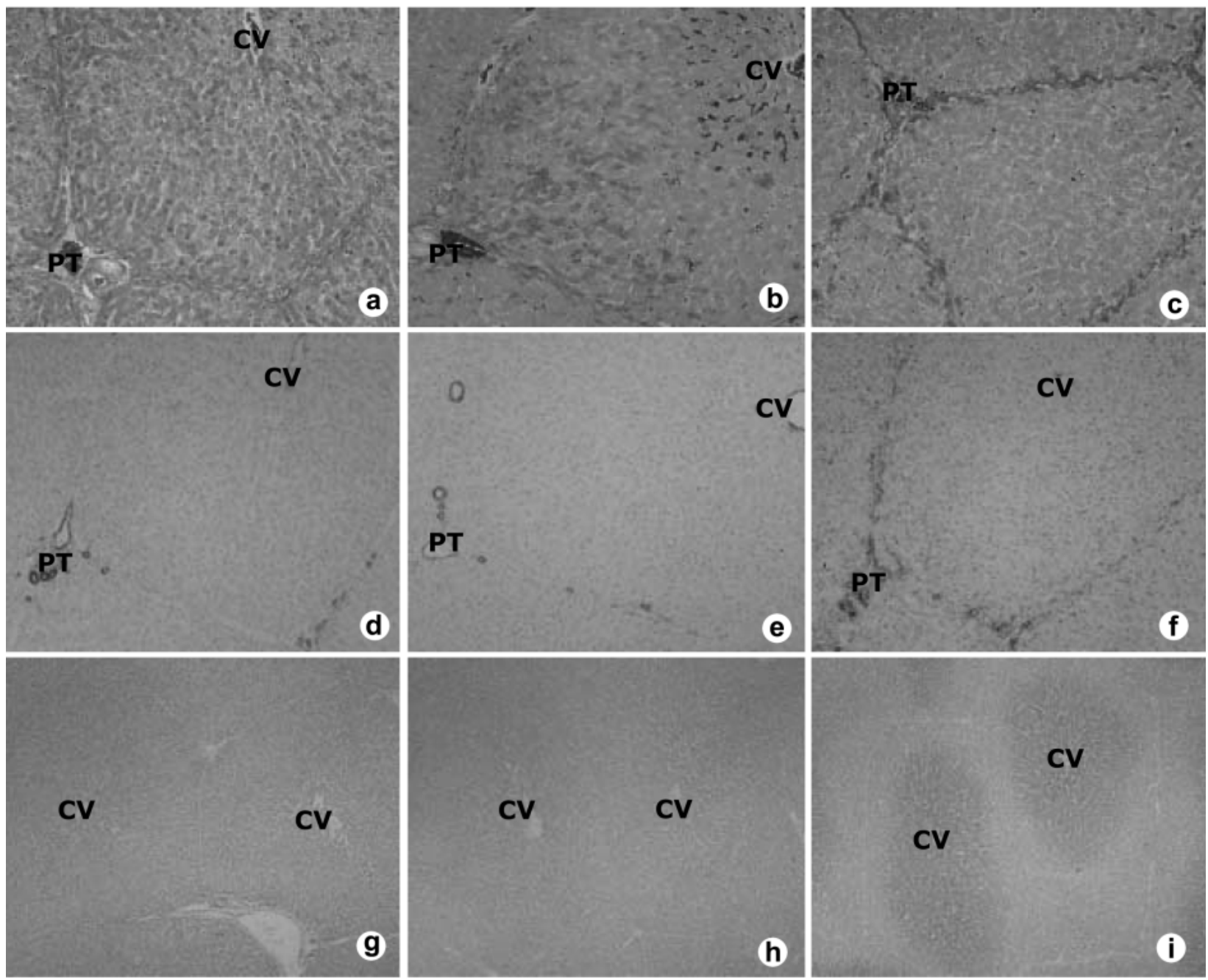

Fig. 3. Histopathological and immunohistochemical findings in alcohol-induced pig liver. Collagen fibers significantly increased in G3 (c) as compared with those of G1 (a) and G2 (b). The livers of G1 (c) and G2 (d) show normal distribution of myofibroblasts. However, in G3 (f), myofibroblasts were identified especially in interlobular septa. CYP2E1 was observed on liver sections from all experimental groups. Virtually constitutive immunoreactive CYP2E1 was observed in G1 (g). However, expression of CYP2E1 was slightly activated around the areas of pericentral veins in G2 pig livers (h), while G3 (i) had significant increase. PT, portal triad; CV, central vein; A-C, Azan stain, $\times 33$; D-F, $\alpha$-SMA immunostain, $\times 13$; G-H, CYP2E1 immunostain, $\times 13$.

compared with those in G1 and G2 (Fig. 3A-C).

Immunohistochemical results: In G3, myofibroblasts (activated hepatic stellate cell and portal fibroblast) were successfully identified by $\alpha$-SMA-positive staining. They appeared as spindle-shaped cell bodies with long processes especially in interlobular septa and areas around the central veins. However, the livers of G1 and G2 showed no and minimum fibrogenesis-dependent $\alpha$-SMA expression, respectively (Fig. 3D-F), indicating inhibition of activation of hepatic stellate cells in these animals of G1 and G2. Ethanol inducible CYP2E1 was observed in liver sections from all experimental groups. Thus, immunoreaction of CYP2E1 was regarded to be normal in hepatocytes around the central veins in the livers of G1. Expression of CYP2E1 was acti- vated in the centrilobular hepatocytes, slightly in the liver of G2, and significantly in that of G3 (Fig. 3G-I).

\section{DISCUSSION}

Alcohol is oxidized primarily in the liver, and the main pathway involves ADH producing acetaldehyde [22, 23]. A toxicological breakthrough was achieved with the discovery of a microsomal ethanol oxidizing system (MEOS) and its interactions with xenobiotics [26]. This pathway for alcohol metabolism is independent from that through ADH and catalase, and may be characterized and reconstituted by a semipurified preparation of cytochrome P-450 [31]. An ethanolinducible form of cytochrome P-450 was discovered and 
subsequently purified from the livers of different species, including rats and humans $[17,32]$. Ethanol oxidation, whether by the ADH or the microsomal pathway, results in acetaldehyde production, which may cause cell damage and subsequently increase AST and ALT in blood.

In the present study, all serum markers of G1 were within the normal range [18, 19], and collagen fibers were observed at the normal amount in the portal areas and interlobular septa of $\mathrm{G} 1$, indicating that there was no hepatic damage. Thus, we designated G1 as the control. In G2 and G3 given diet, the alcohol-induced hepatic damage was found to be present at much less magnitude in G2 than in G3. There was an increase of collagen fibers in the interlobular septa of G3 pig livers (Fig. 3C), while, G2 exhibited no increase of collagen fibers. These data indicated a protective effect of bio-active ceramic water against alcoholinduced hepatic damages and collagen synthesis.

Extracellular matrix constituents in the liver are synthesized by hepatocytes, bile duct epithelial cells, and endothelial cells, but the largest contribution to the extracellular matrix and fibrogenesis comes from mesenchymal myofibroblast-like cells of the liver $[1,2,6,8]$. In the space of Disse, typical HSC, transitional cells (intermediate between HSC and myofibroblasts), and myofibroblasts have been described [3] and identified with immunohistochemical stain for $\alpha$-SMA. Another mesenchymal (myo)fibroblastlike cell type in the liver is the portal (myo)fibroblast [28]. The present study showed that myofibroblasts increased only in ethanol + tap water fed group (G3), especially in the interlobular septa, followed by collagen deposition at the site.

CYP2E1 genes play a critical role in ethanol metabolism in the liver. MEOS was found to be strikingly inducible by chronic ethanol consumption, with its key component, namely 2E1, increased 4- to 10 -fold in liver biopsies of recently drinking subjects [34]. Chronic ethanol intake changes numerous cellular functions, leading to parenchymal damage. Ethanol is primarily metabolized via cytosolic $\mathrm{ADH}$ to acetaldehyde, which is continuously metabolized to acetate in the mitochondria. In the mitochondria, redox reactions convert $\mathrm{NAD}+$ to $\mathrm{NADH}$, and the resulting redox status causes fatty changes, fibrosis, and cirrhosis in the liver. Therefore, inhibition of the CYP2E1 pathway is critical for protection against ethanol-induced hepatoxicity. In the present experiments, we demonstrated a lower activity level of CYP2E1 in the bio-active ceramic water-fed group (G2), while ethanol + tap water-fed group (G3) showed strong reactivity. CYP2E1 is likely to play an important role in the increased generation of reactive oxygen species (ROS) resulting in hepatocyte damage, which is primarily blocked by anti-oxidant enzyme superoxide dimustase (SOD) [13]. It has been reported in our study that eleven proteins were significantly up-regulated in bio-active ceramic water-treated rat liver using by two-dimensional gel electrophoresis and matrix-assisted laser desorption/ionization-time of flight mass spectrometry (MALDI-TOF MS) [35]. The most highly expressed protein of these was SOD with up-regulated enzyme activity, which was confirmed by immunoblots as a major antioxidant capable of detoxifying normally generative reactive oxygen species. These data suggested CYP2E1 dependent protecting mechanism via SOD up-regulation of bio-active ceramic water.

Several animal models of alcoholic liver disease have been established $[25,26]$. However, ethanol intake has been mainly performed by force feeding in most animal models. Recently, some studies using micropig models of alcoholinduced liver disease have been performed [9, 30]. One study reported that the livers from ethanol-fed micropigs showed increased centrilobular CYP2E1 and protein adducts with acetaldehyde and malondialdehyde [9]. Halsted and his colleagues also found that steatohepatitis occurred in five of six pigs which were fed ethanol for 14 weeks [9]. One study reported that perivenous fibrosis was present in three of five micropigs fed ethanol for 12 months and more extensive pericentral and intralobular fibrosis was noted in one micropig fed ethanol for 21 months [30]. Here, our model is based on the predilection of swine voluntarily consuming ethanol in the diet. Our study was conducted by feeding twelve pigs with $15 \%$ ethanol for twelve weeks, resulting in an increase in collagen depositions within the interlobular septa of the liver. Furthermore, increased myofibroblasts and activation of CYP2E1 in the livers of G3 pigs were noted mainly in the interlobular septa and centrilobular areas, respectively. Significantly, portal fibroblasts expressed strong reaction of $\alpha$-SMA in the interlobular areas. However, the reason of portal myofibroblast expression in the interlobular septa instead of pericentral veins was unclear.

Alcoholic hepatitis is characterized by extensive necrosis and inflammation of the liver. Furthermore, these lesions trigger fibrosis as well, suggesting that this is the main mechanism for the development of alcoholic cirrhosis. Because of the potential role of inflammatory factors in the pathogenesis of fibrosis and cirrhosis, therapeutic antiinflammatory treatments have been proposed. In view of the potential fibrogenic role of cytokines, anticytokine therapy is also being contemplated, using either antibodies, inhibitors of cytokine binding, or regulators of cytokine production [4]. Colchicine may provide a useful approach as an anti-inflammatory agent for the treatment of alcoholic liver injury [11]. In patients with alcoholic liver disorders and hepatitis $\mathrm{C}$, no specific antiviral therapy is currently available as alpha-interferon is contradicted in alcoholics. The increase in collagen accumulation induced by acetaldehyde has been prevented by polyenylphosphatidylcholine (PPC) extracted from soybeans [19] and by its main phosphatidylcholine series, dilinoleophosphatidyl choline (DLPC) [25]. More recently, PPC has also been shown to prevent alcoholinduced steatosis and hyperlipemia [29] and to exert an unexpected but potent antioxidant effect [24] of possible relevance to the fibrosis, since the latter is known to be stimulated by products of lipid peroxidation. PPC is now being tested in humans [4]. However, there have been no investigations of anti-fibrotic efficacy of bio-active ceramic water 
on the models of hepatic injury.

So far, we don't see any metabolic change in the body system such as gastrointestinal absorption, but we speculated that the bio-active ceramic water was already activated in the ceramic stone treatment before drinking. Further studies for effective component of bio-active water will be needed.

In conclusion, based on the above data, we suggest that bio-active ceramic water may have a protective capability against ethanol-induced hepatic toxicity and fibrosis in pigs, and that having no toxic effect on the pig liver. The bioactive ceramic water can be useful as a therapeutic drinking water in patients suffering from alcoholic liver diseases.

ACKNOWLEDGEMENT. This research was supported by the Brain Korea 21 Project in 2004.

\section{REFERENCES}

1. Abdel-Aziz, G., Rescan, P. Y., Clement, B., lebeau, G., Rissel, M., Grimauo, J. A., Campion, J. P. and Guillouzo, A. 1991. Cellular sources of matrix proteins in experimentally induced cholestatic rat liver. J. Pathol. 164: 167-174.

2. Andrade, Z. A., Guerret, S. and Fernandes, A. L. 1999. Myofibroblasts in schistosomal portal fibrosis of man. Mem. Inst. Oswaldo Cruz. 94: 87-93.

3. Cassiman, D., Libbrecht, L., Desmet, V., Denef, C. and Roskams, T. 2002. Hepatic stellate cell/myofibroblast subpopulations in fibrotic human and rat livers. J. Hepatol. 36: 200-209.

4. Czaja, M. J., Xu, J. and Alt, E. 1995. Prevention of carbon tetrachloride-induced rat liver injury by soluble tumor necrosis factor receptor. Gastroenterology 108: 1849-1854.

5. Ekstrom, G. and Ingelman-Sundberg, M. 1989. Rat liver microsomal NADPH-supported oxidase activity and lipid peroxidation dependent on ethanol-inducible cytochrome P450. Biochem. Pharmacol. 38: 1313-1318.

6. Friedman, S. L. 1993. The cellular basis of hepatic fibrosis : Mechanism and treatment strategies. New. Engl. J. Med. 328: $1828-1835$.

7. Friedman, S. L. 1997. Molecular mechanisms of hepatic fibrosis and principles of therapy. J. Gastroenterol. 32: 424-430.

8. Gressner, A. M. 1994. Perisinusoidal lipocytes and fibrogenesis. Gut 35: 1331-1333.

9. Halsted, C. H., Villanueva, J. A., Devlin, A. M., Niemela, O., Parkkila, S., Garrow, T. A., Wallock, L. M., Shigenaga, M. K., Melnyk, S. and James, S. J. 2002. Folate deficiency disturbs hepatic methionine metabolism and promotes liver injury in the ethanol-fed micropig. Proc. Natl. Acad. Sci. U.S.A. 99: 1007210077.

10. Karsenty, C., Baraona, E., Savolainen, M. J. and Lieber, C. S. 1985. Effects of chronic ethanol intake on mobilization and excretion of cholesterol in baboons. J. Clin. Invest. 75: 976986.

11. Kershenobich, D., Vargas, F., Garcia-Tsao, G., Perez Tamayo R., Gent, M. and Rojkind, M. 1988. Colchicine in the treatment of cirrhosis of the liver. New. Engl. J. Med. 318: 1709-1713.

12. Knecht, K. T., Bradfort, B. U., Mason, R. P. and Thurman, R. G. 1990. In vivo formation of a free radical metabolite of ethanol. Mol. Pharmacol. 38: 26-30.

13. Koch, O. R., Pani, G., Borrello, S., Colavitti, R,, Cravero, A., Farre, S. and Galeotti, T. 2004. Oxidative stress and antioxi- dant defenses in ethanol-induced cell injury. Mol. Aspects. Med. 25: 191-198.

14. Ramadori, G., Knittel, T. and Saile, B. 1998. Fibrosis and altered matrix synthesis. Digestion 59: 372-375.

15. Reinke, L. A., Lai, E. K., DuBose, C. M. and McCay, P. B. 1987. Reactive free radical generation in vitro in heart and liver of ethanol-fed rats: correlation with radical formation in vitro. Proc. Natl. Acad. Sci. U.S.A. 84: 9223-9227.

16. Schull, M. M., Ormsby, I., Kier, A. B., Pawlowski, S., Diebold, R. J., Yin, M., Allen, R., Sidman, C., Proetzel, G., Calvin, D., Annunzata, N. and Doetschman, T. 1992. Targeted disruption of the mouse transforming growth factor-beta 1 gene results in multifocal inflammatory disease. Nature (Lond.) 359: 693699.

17. Lasker, J. M., Raucy, J., Kubota, S., Bloswick, B. P., Black, M. and Lieber, C. S. 1987. Purification and characterization of human liver cytochrome P-450-ALC. Biochem. Biophys. Res. Commun. 148: 232-238.

18. Leman, A. D., Straw, B., Clock R. D., Mengeling, W. L., Renny, R. H. C. and Scholl, E. 1982. Diseases of Swine. pp. 35-39. In: Hematology and Clinical Chemistry, 6th ed. (Tumbleson M.E., Schmidt D.A. and Scholl E. ed.), Iowa State University Press, Iowa.

19. Leman, A. D., Straw, B. E., Mengeling, W. L., D'allaire, S. and Taylor, D. J. 1992. Diseases of swine. p. 9. In: Cardiovascular System, Hematology, and Clinical Chemistry, 7th ed., (Friendship R.M. and Henry S.C., ed.), Iowa State University Press, Iowa.

20. Li, J., Kim, C. I., Leo, M. A., Mak, K. M., Rojkind, M. and Lieber, C. S. 1992. Polyunsaturated lecithin prevents acetaldehyde-mediated hepatic collagen accumulation by stimulating collagenase activity in cultured lipocytes. Hepatology 15: 373 381.

21. Lieber, C. S. 1993. Biochemical factors in alcoholic liver disease. Semin. Liver Dis. 13: 136-153.

22. Lieber, C. S. 2000. Alcoholic liver disease : new insights in pathogenesis lead to new treatments. J. Hepatol. 32: 113-128.

23. Lieber, C. S. 2000. Alcohol and the liver: metabolism of alcohol and its role in hepatic and extrahepatic diseases. Mt. Sinai J. Med. 67: 84-94.

24. Lieber, C. S., Leo, M. A., Aleynik, S. I., Aleynik, M. K. and DeCarli, L. M. 1997. Polyenylphosphatidylcholine decreases alcohol-induced oxidative stress in the baboon. Alcohol. Clin. Exp. Res. 21: 375-379.

25. Lieber, C. S., Robins, S. J., Li, J., DeCarli, L. M., Mak, K. M., Fasulo, J. M. and Leo, M. A. 1994. Phosphatidylcholine protects against fibrosis and cirrhosis in the baboon. Gastroenterology 106: 152-159.

26. Lieber, C. S. and DeCarli, M. 1970. Hepatic microsomal ethanol oxidizing system: In vitro characteristics and adaptive properties in vivo. J. Biol. Chem. 245: 2505-2512.

27. Lieber, C. S. and DeCarli, L. M. 1974. An experimental model of alcohol feeding and liver injury in the baboon. J. Med. Primatol. 3: 153-163.

28. Nakano, M. and Lieber, C. S. 1982. Ultrastructure of initial stages of perivenular fibrosis in alcohol fed baboons. Am. J. Pathol. 106: 145-155.

29. Navder, K. P., Baraona, E. and Lieber, C. S. 1997. Polyenylphosphatidylcholine attenuates alcohol-induced fatty liver and hyperlipemia in rats. J. Nut. 127: 1800-1806.

30. Niemela, O., Parkkila, S., Yla-Herttuala, S., Villanueva, J., Ruebner, B. and Halsted, C. H. 1995. Sequential acetaldehyde production, lipid peroxidation, and fibrogenesis in micropig 
model of alcohol-induced liver disease. Hepatology 22: 12081214.

31. Ohnishi, K. and Lieber, C. S. 1977. Reconstitution of the microsomal ethanol-oxidizing system: Qualitative and quantitative changes of cytochrome P-450 after chronic ethanol consumption. J. Biol. Chem. 252: 7124-7131.

32. Ryan, D. E., Iida, S., Wood, A. W., Thomas, P. E., Lieber, C. S. and Levin, W. 1984. Characterization of three highly purified cytochromes P-450 from hepatic microsomes of adult male rats. J. Biol. Chem. 259: 1239-1250.

33. Savolainen, M. J., Baraona, E., Leo, M. A. and Lieber, C. S. 1986. Pathogenesis of the hypertriglyceridemia at early stages of alcoholic liver injury in the baboon. J. Lipid Res. 27: 1073 1083.

34. Shaw, S., Rubin, K. P. and Lieber, C. S. 1983. Depressed hepatic glutathione and increased diene conjugates in alcoholic liver disease. Evidence of lipid peroxidation. Dig. Dis. Sci. 28: $585-589$.

35. Yun, H. S., Jeong, W. I., Do, S. H., Jeong, D. H., Jung, Y. R., Park, J. K., Cho, E. M. and Jeong, K. S. 2004. Proteome analysis by bio-active ceramic water in rat liver: contribution to antioxidant enzyme expression, SDO I. Biochem. Biophys. Res. Commun. 320: 852-859 (in press). 